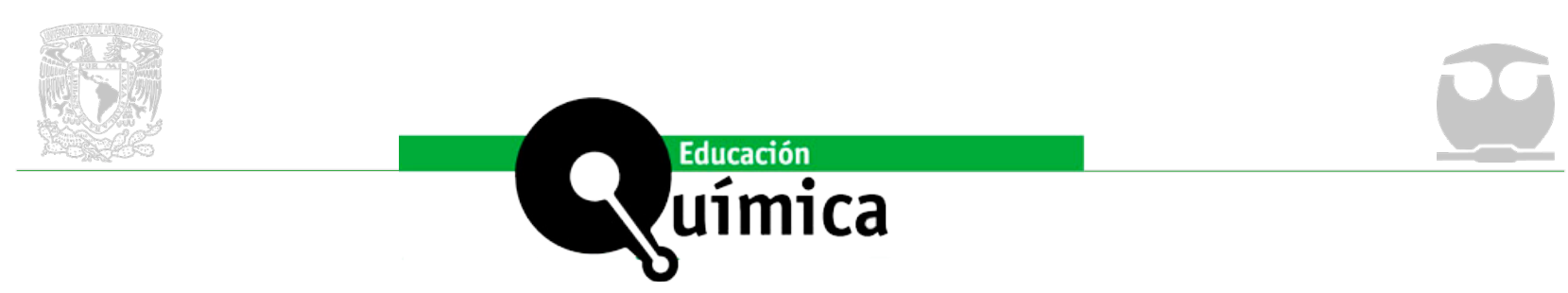

\title{
El Antropoceno. Riesgos y oportunidades para las nuevas generaciones
}

\author{
The Anthropocene. Risks and opportunities for the new generations
}

Amparo Vilches y Daniel Gil Pérez ${ }^{1}$

\begin{abstract}
Resumen
Nuestro propósito en este trabajo es presentar la estrategia que venimos utilizando desde hace más de dos décadas para contribuir a implicar a diversos sectores de la ciudadanía $-\mathrm{y}$, muy especialmente, a estudiantes y docentes en formación- en la comprensión de la actual situación de emergencia planetaria, caracterizada por un conjunto de graves problemas socioambientales de origen antrópico, que han conducido a denominar Antropoceno la presente etapa de la evolución del planeta. Analizaremos las causas y consecuencias de estos problemas estrechamente vinculados $y$ que se potencian mutuamente, provocando la transgresión de diversos límites planetarios. Y nos centraremos en las posibles medidas para hacerles frente y avanzar hacia sociedades sostenibles, respetuosas del conjunto de Derechos Humanos Universales, incluido el derecho fundamental a un ambiente saludable.
\end{abstract}

Palabras clave:

Antropoceno; Emergencia planetaria; Límites planetarios; Objetivos de Desarrollo Sostenible (ODS); Transición a la Sostenibilidad.

\begin{abstract}
Our purpose with this paper is to expound the strategy we have been using during more than two decades in order to involve citizens -and, very particularly, students and educators in trainingin a sound understanding of the current situation of planetary emergency, characterized by a set of serious socio-environmental problems of anthropic origin, which have led to name the present stage of the evolution of the planet as Anthropocene. We will analyse the causes and consequences of these closely linked and mutually reinforcing problems which cause dangerous transgressions of several planetary boundaries. And we will focus on the feasible measures to face them, in order to move towards sustainable societies, respectful of the ensemble of Universal Human Rights, including the fundamental right to a healthy environment.
\end{abstract}

Keywords:

Anthropocene; Planetary limits; Sustainable Development Goals (SDG); Sustainability transition.

${ }^{1}$ Departamento de Didáctica de las Ciencias Experimentales y Sociales, Universitat de València. 
"El Antropoceno. Riesgos y oportunidades para las nuevas generaciones",

Amparo Vilches y Daniel Gil Pérez

Volumen 32 | Número especial | Páginas 55-72 | http://dx.doi.org/10.22201/fq.18708404e.2021.4.80342

\section{Introducción}

$\mathrm{E}$ ste artículo sobre los riesgos y oportunidades que el Antropoceno plantea a las nuevas generaciones se inspira en el Dr. Mario Molina, cuya vida y obra constituyen un excelente ejemplo de lo que significa hacer frente a los graves problemas glocales (a la vez globales y locales) de esta nueva etapa de la historia de la Tierra. Tenemos presente, en primer lugar, su actividad científica en torno al proceso de destrucción de la capa de ozono estratosférico que protege al planeta de la radiación ultravioleta. Esta destrucción, causada por los compuestos Cloro-Flúor-Carbonados (CFC), utilizados en objetos y tareas como los sistemas de refrigeración, había puesto en peligro a buena parte de la biosfera, incluida la especie humana, y las investigaciones del Dr. Molina - por las que obtuvo el Premio Nobel en 1995 junto a Frank S. Rowland y Paul Crutzen- contribuyeron a comprender el problema y a concebir soluciones.

Pero tan importante como su investigación fue su permanente labor educativa y su decidida implicación en lograr, en 1987, un acuerdo mundial para la sustitución de los CFC por sustancias menos dañinas para la capa de ozono. Este acuerdo, conocido como Protocolo de Montreal, entró en vigor el 1989 y ha logrado interrumpir la destrucción de la capa de ozono e iniciar su recuperación. De este modo, las actividades científicas, educativas y ciudadanas de Mario Molina, convergieron en la resolución de un grave problema, convirtiendo la detección del riesgo y el estudio de sus causas y posibles soluciones en oportunidad de avance para toda la humanidad. Un excelente ejemplo de lo que se precisa para hacer frente al conjunto de problemas que caracterizan el Antropoceno.

Como el propio Molina ha expresado, "Los científicos pueden plantear los problemas que afectarán al medio ambiente con base en la evidencia disponible, pero su solución no es responsabilidad de los científicos, es de toda la sociedad". Esta importancia concedida por el Dr. Molina al papel de la sociedad -y, por tanto, a la educación y a la acción ciudadanaen la resolución de los problemas, explica su decisión de retornar a México y dirigir el Centro Mario Molina, creado en 2004 para realizar investigaciones conectadas a políticas públicas de protección al medio ambiente, estudiando nuevos problemas consecuencia de actividades humanas, como el cambio climático, que aparecían estrechamente vinculados entre sí. Así, por ejemplo, se comprendió pronto que los compuestos hidro-flúorcarbonados utilizados para sustituir a los CFC tenían un gran poder de efecto invernadero, contribuyendo a intensificar el desarreglo climático. La problemática socio-ambiental evidenciaba así su complejidad y reclamaba la confluencia de medidas y enfoques diversos que debían ser contemplados conjuntamente.

Naturalmente, otros investigadores coincidían con el Dr. Molina en estas preocupaciones y planteamientos. Resulta significativo que el nombre de Antropoceno fuera introducido por Paul Crutzen, uno de los tres laureados con el Premio Nobel de Química de 1995, junto a Frank S. Rowland y el propio Mario Molina. Nos lo recuerda el periodista científico Fred Pearce, reproduciendo las palabras con las que Crutzen le explicó cómo llegó a ver la necesidad de acuñar ese nuevo concepto para dejar constancia de la responsabilidad humana en los grandes cambios experimentados por nuestro planeta: "Estaba en un congreso en el que alguien dijo algo sobre el Holoceno, el largo periodo de clima relativamente estable que siguió a la última era glaciar. De pronto me di cuenta de que aquello era un error. El mundo ha cambiado mucho, así que dije 'No, estamos en el antropoceno'. Inventé la palabra [Antropoceno] estimulado por el debate. Todo el mundo se quedó estupefacto. Pero parece que ha cuajado" (Pearce, 2007, página 59). 
"El Antropoceno. Riesgos y oportunidades para las nuevas generaciones",

Amparo Vilches y Daniel Gil Pérez

Volumen 32 | Número especial | Páginas 55-72 |

Este mérito de Crutzen en la invención del concepto de Antropoceno lo recoge también Jeffrey Sachs, economista y profesor de Desarrollo Sostenible del Instituto de la Tierra de la Universidad de Columbia, en su libro Economía para un planeta abarrotado: "El premio Nobel de Química Paul Crutzen ha apodado a nuestro tiempo como el Antropoceno, una era en que la Tierra está dominada por el ser humano, porque el volumen de las actividades humanas es ahora tan grande que ha desbaratado todos los sistemas fundamentales para el sostenimiento de la vida" (Sachs, 2008, p. 101). Poco después de la iniciativa de Crutzen, el nombre de Antropoceno fue propuesto de forma oficial a la International Commission on Stratigraphy (ICS) por geólogos de la Universidad de Leicester y de la Comisión de Estratigrafía de la Geological Society of London, con los mismos argumentos de la responsabilidad de nuestra especie en los grandes cambios experimentados por el planeta (Zalasiewicz et al., 2008).

Numerosos trabajos habían ido mostrando esta responsabilidad de las actividades humanas, y el conocido ecólogo de la Universidad de Stanford Peter Vitousek y sus colegas Harold Mooney, Jane Lubchenco y Jerry Melillo resumían así el resultado de muchas investigaciones, incluidas las suyas propias: "Entre un tercio y la mitad de la superficie terrestre ha sido transformada por la acción humana; la concentración de dióxido de carbono en la atmósfera se ha incrementado en cerca de un 30\% desde el comienzo de la Revolución Industrial; la humanidad ha fijado más nitrógeno atmosférico que el conjunto de todas las fuentes naturales terrestres; más de la mitad de toda el agua dulce accesible está siendo utilizada por la humanidad". Y concluían: "mantener la diversidad de las especies 'silvestres' y el funcionamiento de los ecosistemas 'naturales' exigirá una creciente implicación de la humanidad" (Vituosek et al., 1997). Precisamente, la actividad científica, educativa y ciudadana de Mario Molina constituyen un ejemplo de esta necesaria implicación para poner fin a los graves problemas a los que se enfrenta la humanidad.

Nuestro propósito en este trabajo, como educadores e investigadores en el área de la educación científica es, en primer lugar, sintetizar el conjunto de problemas socioambientales de origen entrópico, estrechamente vinculados, que caracterizan el Antropoceno, sus causas y las necesarias medidas para avanzar hacia sociedades sostenibles, respetuosas del conjunto de Derechas Humanos, incluido el derecho fundamental a un ambiente saludable. Y aprovechar esta síntesis para presentar la estrategia que venimos utilizando desde hace más de dos décadas para contribuir a implicar a diversos sectores de la ciudadanía -y, muy especialmente, a docentes y estudiantes de Secundaria y universidad- en la comprensión de la actual situación de emergencia planetaria y en la adopción de medidas fundamentadas para hacer frente a sus riesgos, aprovechando las oportunidades de reorientación que esta profunda crisis ofrece.

\section{Una propuesta de Educación para la Sostenibilidad en el Antropoceno}

Nuestro trabajo de educación para la Sostenibilidad se inició, bastante antes de que el concepto de Antropoceno fuera aceptado por la comunidad científica, en respuesta a llamamientos de Naciones Unidas -como los realizados durante la Conferencia de La Tierra en Río de Janeiro (1992)- para que la educación contribuya a la preparación de la ciudadanía para hacer frente a la situación de crisis planetaria que estamos viviendo. Estos llamamientos se han dirigido a educadores y educadoras de todas las materias y niveles, incluidos responsables de la educación "no reglada" (museos, medios de comunicación...) 
"El Antropoceno. Riesgos y oportunidades para las nuevas generaciones", Amparo Vilches y Daniel Gil Pérez

y proponen, en esencia, impulsar una educación que contribuya a una correcta percepción de los problemas que afectan a la humanidad, genere actitudes y comportamientos responsables y prepare para la acción y la toma de decisiones fundamentadas. Se puede y debe contribuir a ello aprovechando las numerosas ocasiones que cualquier materia curricular ofrece para referirse a diversos problemas a los que se enfrenta hoy nuestra especie (Vilches y Gil Pérez, 2011), pero consideramos también necesario dedicar un módulo específico a abordar globalmente esta problemática de la situación del mundo, para mejor preparar el aprovechamiento de las diversas contribuciones concretas que puedan hacerse vinculadas al contenido de las distintas materias. Presentamos seguidamente una síntesis de las actividades esenciales de una versión de este módulo que, adaptado a cada situación y desde el marco del Antropoceno, hemos impartido también con resultados positivos en talleres de educación ciudadana.

La situación de partida de la mayoría de estudiantes, docentes y ciudadanía en general, por lo que se refiere a su percepción de los problemas a los que se enfrenta hoy la humanidad, se ajusta a lo que se describe como el síndrome de "la rana hervida" (Gore, 2007). Consideramos conveniente, por ello, comenzar nuestro módulo planteando la siguiente actividad para llamar su atención e iniciar su trabajo en pequeños grupos:

Posiblemente han oído hablar del síndrome de la rana hervida. Recordémoslo: si intentamos introducir una rana en agua muy caliente, da un salto y escapa; pero si la introducimos en agua a temperatura ambiente y procedemos a calentarla lentamente, la rana permanece en el agua hasta morir hervida. ¿Qué explicación podemos dar a este comportamiento? ¿Qué lecciones pueden extraerse?

Tras una breve discusión en el seno de los equipos, la puesta en común permite sintetizar una explicación plausible y consensuada: la rana no percibe la gravedad de los cambios paulatinos, se va adaptando a los mismos, insensibilizándose, y permanece por ello en el agua hasta morir hervida (¡si no la sacamos antes!). Y la pregunta que los participantes en nuestros talleres se formulan es ¿No nos estará pasando lo mismo a los seres humanos?

La cuestión estriba, pues, en prestar atención continuada a los cambios que se están produciendo y lograr que la especie humana reaccione y "salte" antes de sucumbir víctima insensible de los "pequeños cambios". Es importante aprovechar esta reflexión colectiva para contribuir a superar la idea errónea de que los problemas evolucionan de forma lineal, lenta y controlable, por lo que podremos reaccionar fácilmente en cualquier momento para revertir la situación. Basta considerar lo que está suponiendo el deshielo del permafrost o el aumento del efecto Albedo, para comprender que los problemas no son lineales, sino que se retroalimentan y aceleran.

Este es un objetivo central de este módulo: contribuir a que devengamos conscientes, cuanto antes, de la gravedad de una evolución que puede hacerse irreversible, profundizar en sus causas y fundamentar las medidas que debemos y todavía podemos adoptar, aunque el tiempo disponible para hacerlo se acorta peligrosamente. Insistimos así, desde el primer momento, en que aún estamos a tiempo de actuar, pero que es urgente comenzar ya. Esa es la posición de investigadores que han advertido de los mayores peligros y han insistido, incluso, en la posibilidad, nada remota, de un colapso de las sociedades humanas, rechazando tanto la inatención como el pesimismo paralizante (Diamond, 2006). De acuerdo con ello, la tarea que proponemos ahora a los pequeños grupos es la siguiente: 
"El Antropoceno. Riesgos y oportunidades para las nuevas generaciones", Amparo Vilches y Daniel Gil Pérez

Enumerar los problemas a los que, en su opinión, hemos de hacer frente hoy los seres humanos. Es preciso hacer un esfuerzo para no olvidar ningún problema importante porque, como veremos, están estrechamente relacionados, e ignorar alguno puede bloquear el tratamiento del conjunto. (Cotejaremos después su relación con las aportaciones de la comunidad científica).

Se trata, como puede verse, de una pregunta abierta que pretende evitar la focalización de la reflexión colectiva en torno a algunos problemas concretos - aunque sean tan graves como los que plantea, por ejemplo, el cambio climático- olvidando otros igualmente importantes, porque ignorar alguno puede bloquear el tratamiento del conjunto, dada su estrecha vinculación, que se pondrá en evidencia al discutir dichos problemas.

Insistimos en que no estamos solicitando respuestas fruto de estudios previos: no se trata de reproducir un conocimiento ya estudiado, sino de dar respuestas tentativas, fruto de sus experiencias, conjeturas y razonamientos. Les avanzamos, además, nuestra expectativa de que los problemas sugeridos por el conjunto de los equipos, cubrirá la casi totalidad de los detectados por numerosas investigaciones rigurosas, cuyos resultados les aportaremos para reforzar sus contribuciones. Es importante insistir en ello, tanto por su valor motivador, como porque su reflexión y la discusión colectiva les permitirá, después, comprender mejor la información fruto de numerosas investigaciones que les proporcionaremos.

Se genera así una reflexión y discusión muy dinámicas, durante las cuales se producen fecundaciones cruzadas entre los equipos, lo que puede potenciarse, por ejemplo, invitando a algún equipo a exponer sus conclusiones iniciales y pidiendo al conjunto que las comenten y completen con nuevas aportaciones.

De hecho, aunque las aportaciones de cada equipo suelen proporcionar inicialmente visiones incompletas, el conjunto de las contribuciones finales de los distintos equipos suele cubrir buena parte de los aspectos señalados por las investigaciones, aunque, lógicamente, en forma de referencias embrionarias. Es preciso por ello plantearles nuevas actividades (incluyendo la recopilación y comentario de noticias de actualidad, la realización de visitas reales o virtuales a museos, la discusión de algunos breves textos...) que permitan profundizar en los distintos problemas y comprender sus vinculaciones. Así, por ejemplo, dado que el problema de la contaminación ambiental es uno de los primeros en ser mencionados por los equipos, merece la pena proponerles que profundicen en el mismo planteándoles una tarea como esta:

Conviene hacer un esfuerzo por profundizar en lo que supone cada uno de los problemas mencionados:

Comenzando por la contaminación, enumeren las distintas formas que conciban de la misma y las consecuencias que les atribuyen.

Las aportaciones en torno a la contaminación suelen ser ahora numerosasy, en general, pertinentes, permitiendo concluir, de acuerdo con los numerosos estudios realizados al respecto, que esta contaminación ambiental es debida a las actividades humanas, no conoce hoy fronteras y afecta a todo el planeta. Puede ser esta una buena ocasión para introducir la idea de Antropoceno, en relación con el impacto de las actividades humanas sobre el planeta. Como formas de contaminación son frecuentes las referencias a:

- La contaminación del aire debido a la calefacción, al transporte, a las producciones industriales, a los abonos y herbicidas utilizados por la agricultura industrial...

- La contaminación de las aguas superficiales y subterráneas, por los vertidos sin depurar de líquidos contaminantes, de origen industrial, agrícola y urbano... 
"El Antropoceno. Riesgos y oportunidades para las nuevas generaciones",

Amparo Vilches y Daniel Gil Pérez

Volumen 32 | Número especial | Páginas 55-72 | http://dx.doi.org/10.22201/fq.18708404e.2021.4.80342

- La contaminación de los suelos, además de por los líquidos contaminantes, por residuos sólidos como plásticos no biodegradables, material electrónico, metales pesados...

- En esta contaminación del aire, suelos y aguas (que en buena parte termina en el mar) están incidiendo de forma notable los accidentes asociados a la producción, transporte y almacenaje de materias peligrosas (radiactivas, metales pesados, petróleo...).

- Cabe, por otra parte, detenerse en otras formas de contaminación, en general menos señaladas, pero igualmente perniciosas como, entre otras:

- la contaminación acústica -asociada a la actividad industrial, al transporte y a una inadecuada planificación arquitectónica y urbanística- y causa de graves trastornos físicos y psíquicos;

- la contaminación lumínica que en las ciudades afecta al reposo nocturno de los seres vivos;

- la contaminación visual que provoca, por ejemplo, el abandono de residuos en las ciudades y en la naturaleza, las construcciones industriales y urbanas carentes de estética, etc.;

- la contaminación del espacio próximo a la Tierra con la denominada "chatarra espacial" (cuyas consecuencias pueden ser funestas para la red de comunicaciones que ha convertido nuestro planeta en una aldea global);

- ...

Entre las secuelas más graves de la contaminación se suele mencionar la destrucción de la capa de ozono, la lluvia ácida, el deterioro de bosques y tierras cultivables, así como de las vías fluviales, lagos y mares... con una atención muy particular al cambio climático global (algo que apenas era mencionado, conviene señalar, hace menos de dos décadas). Estas secuelas de la contaminación conectan con la destrucción de los recursos naturales, poniendo en evidencia la estrecha vinculación de los problemas. Así, al hablar de la lluvia ácida y demás causas del deterioro de los bosques, se señala cómo ello contribuye a una grave reducción de la masa boscosa, causa, a su vez, de aumento del efecto invernadero $\mathrm{y}$, por tanto, del avance del cambio climático y consiguiente incremento de la frecuencia e intensidad de los fenómenos atmosféricos extremos, que agravan el deterioro de los ecosistemas, la destrucción de la biodiversidad y, en definitiva, la reducción de los recursos naturales. Problemas que a su vez están contribuyendo al incremento de la pobreza y las crecientes desigualdades... Vamos poniendo así de manifiesto que todos los problemas socioambientales están estrechamente vinculados entre sí y se potencian mutuamente, lo que obliga a un tratamiento conjunto de los mismos. En ello ha insistido, entre otros, Jared Diamond, afirmando, tras analizar la docena de graves problemas a los que se enfrentan nuestras sociedades: "Si no resolvemos cualquiera de la docena de problemas sufriremos graves perjuicios (...) porque todos ellos se influyen mutuamente" (Diamond, 2006, p. 645).

Actividades similares a esta que hemos dedicado a profundizar en la contaminación, se destinan a centrar la atención en el agotamiento de los recursos esenciales - tanto por la contaminación ya estudiada, como por los excesos de consumo y las ineficiencias en su extracción y uso- y demás problemas mencionados a la vez que se comprende cómo dichos problemas se potencian en las ciudades. Una urbanización creciente y desordenada relacionada con el abandono del mundo rural y que junto con los problemas estudiados contribuye a la degradación de todos los ecosistemas con graves consecuencias tanto ambientales como sociales (incremento de la pobreza, disminución de la diversidad biológica y cultural, enfermedades, conflictos y violencias que a su vez contribuyen a la 
"El Antropoceno. Riesgos y oportunidades para las nuevas generaciones", Amparo Vilches y Daniel Gil Pérez

degradación, etc.). Se contempla, así mismo, lo que para expertos en sostenibilidad está detrás del conjunto de problemas analizados: un crecimiento económico y demográfico continuado en un planeta de recursos limitados, asociado al hiperconsumo de las sociedades desarrolladas y causante de enormes desequilibrios que generan conflictos y violencias...

El resultado de todo el trabajo realizado por los equipos - que no seguiremos detallando aquí por razones de espacio- culmina con la confección de un esquema o mapa conceptual de los problemas tratados y sus vinculaciones, que pueden cotejar después con una síntesis que les proporcionamos (Tabla 1), obtenida a partir de las aportaciones convergentes de numerosos equipos de docentes de todos los niveles y de diversos países (Gil Pérez et al., 2003) que se ha ido actualizando y del análisis de la abundante literatura existente acerca de la situación de emergencia planetaria.

1) Hacer frente a los problemas generados por un crecimiento económico y demográfico al servicio de intereses y valores particulares y a corto plazo, que externaliza (es decir, no toma en consideración) sus repercusiones ambientales y sociales.

Dicho crecimiento se traduce en una serie de problemas específicos, pero estrechamente relacionados:

1.1. Una urbanización creciente y, a menudo, desordenada y especulativa, acompañada del abandono y deterioro del mundo rural.

1.2. Contaminación ambiental pluriforme y sin fronteras con graves secuelas "glocales" (a la vez locales y globales): lluvia ácida, destrucción de la capa de ozono, incremento del efecto invernadero (causa principal del Cambio Climático), etc.

1.3. Agotamiento y destrucción de los recursos (yacimientos minerales, capa fértil de los suelos, recursos de agua dulce, masa forestal...).

1.4. Degradación de todo tipo de ecosistemas (incluidos los espacios humanizados), destrucción de la biodiversidad (causa de enfermedades como las pandemias provocadas por las zoonosis, hambrunas...) y, en última instancia, desertificación.

1.5. Destrucción, muy en particular, de la diversidad cultural, fruto esencial del desarrollo humano.

\section{2) Poner fin a las siguientes causas (y, a su vez, consecuencias) de este crecimiento insostenible:}

2.1. El hiperconsumo depredador de las sociedades "desarrolladas" y grupos poderosos, asociado a un crecimiento económico continuado (insostenible en un planeta finito), que resulta agresivo con el medio físico y nocivo para los seres vivos, fruto de comportamientos guiados por intereses y valores particulares y a corto plazo.

2.2. Un crecimiento demográfico que amenaza con superar la capacidad de carga del planeta y pone en peligro al conjunto de la biosfera (cerca de la mitad de la producción fotosintética primaria anual de los ecosistemas es usada ya por la especie humana).

2.3. Los desequilibrios existentes entre distintos grupos humanos — asociados a falta de libertades e imposición de valores e intereses particulares competitivos y a corto plazo- que se traducen en hambre, pobreza, discriminación étnica, de género... y, en general, marginación de amplios sectores de la población.

2.4. Las distintas formas de conflictos y violencias asociados, a menudo, a dichos desequilibrios: 2.4.1. Las violencias de clase, género, interétnicas, interculturales... y los conflictos bélicos (con sus secuelas de carrera armamentística, destrucción...).

2.4.2. La actividad de las organizaciones mafiosas que trafican con armas, drogas y personas, contribuyendo decisivamente a la violencia ciudadana.

TABla 1. Problemas y desafíos a los que debe hacer frente hoy la humanidad
2.4.3. La actividad especuladora y depredadora de empresas transnacionales que escapan al control democrático -imponiendo condiciones de explotación destructivas de personas y medio físico- y eluden sus obligaciones fiscales a través de los llamados refugios o paraísos fiscales. 
"El Antropoceno. Riesgos y oportunidades para las nuevas generaciones",

Amparo Vilches y Daniel Gil Pérez

Volumen 32 | Número especial | Páginas 55-72 |

http://dx.doi.org/10.22201/fq.18708404e.2021.4.80342

Conviene señalar, que la atención inicial a los distintos problemas que aparecen en la Tabla 1 no es uniforme, ni por parte de los asistentes a nuestros cursos, ni por los medios de comunicación, y ni siquiera por la comunidad científica: mientras la contaminación, el agotamiento de recursos, la pérdida de biodiversidad o los desequilibrios extremos son contemplados de forma generalizada por la mayoría de los equipos participantes, hay tres problemas -concretamente el de una urbanización desordenada, la pérdida de diversidad cultural y el crecimiento demográfico- que pese a su gravedad, a menudo son inicialmente ignorados, incluso por docentes (Gil Pérez et al., 2003; Vilches y Gil Pérez, 2020), sin apenas diferencias estadísticas entre colectivos de distintos países. Por el contrario, una vez dichos problemas son introducidos por algún equipo y se discuten argumentos fundamentados, su importancia llega a ser plenamente reconocida, venciendo ignorancias y resistencias iniciales.

Podemos referirnos, a título de ejemplo especialmente preocupante, a la fuerte resistencia social a aceptar que un crecimiento indefinido de la población pueda plantear un serio problema que afecta además al resto de problemas socioambientales. Una resistencia debida al desconocimiento de los datos científicos y a prejuicios religiosos y políticos muy enraizados (Vilches y Gil Pérez, 2020). En el debate de esta cuestión, es necesario aportar informaciones debidamente contrastadas, como las siguientes:

- A lo largo del siglo XX la población mundial se ha casi cuadriplicado. Y aunque ahora se esté produciendo un descenso en la tasa de crecimiento de la población, esta sigue aumentando en unos 80 millones cada año, por lo que puede duplicarse de nuevo en pocas décadas. La Comisión Mundial del Medio Ambiente y del Desarrollo señaló hace ya más de 30 años las consecuencias de este crecimiento: En muchas partes del mundo, la población crece según tasas que los recursos ambientales disponibles no pueden sostener, tasas que están sobrepasando todas las expectativas razonables de mejora en materia de vivienda, atención médica, seguridad alimentaria o suministro de energía (CMMAD, 1988).

- Alrededor de un $40 \%$ de la producción fotosintética primaria de los ecosistemas terrestres es usado por la especie humana cada año para, fundamentalmente, comer, obtener madera, leña para hacer fuego, etc. Es decir, la especie humana está próxima a consumir anualmente tanto como el conjunto de las demás especies (Diamond, 2006).

- Como ya explicaron los expertos en Sostenibilidad, en el marco del llamado Foro de Río + 5 (celebrado por Naciones Unidas en 1997), la actual población precisaría de los recursos de tres Tierras (!) para alcanzar un nivel de vida semejante al de los países desarrollados. Puede decirse, pues, que hemos sobrepasado ya la capacidad de carga del planeta, es decir, la máxima cantidad de seres humanos que el planeta puede mantener de forma permanente en condiciones de vida aceptables para todos. De hecho, se ha estimado que, en la actualidad, la biocapacidad del planeta (es decir el terreno productivo disponible para satisfacer las necesidades humanas) es de alrededor de 1.6 gha (hectáreas por habitante o hectáreas globales), mientras que su huella ecológica (área de territorio productivo necesaria para producir los recursos utilizados y para asimilar los residuos generados) supera ya las 2,8 gha. En definitiva, estas estimaciones globales indican que, aunque se distribuyeran mejor los recursos, evitando las desigualdades inaceptables que hoy se dan, la huella ecológica del conjunto de la población superaría ampliamente la biocapacidad de la Tierra. 
"El Antropoceno. Riesgos y oportunidades para las nuevas generaciones", Amparo Vilches y Daniel Gil Pérez

El análisis y debate de los diferentes argumentos fundamentados en el seno de los equipos, y en la puesta en común posterior, permiten consensuar la necesidad de considerar el crecimiento demográfico como un serio problema, junto al consumismo de las sociedades desarrolladas y demás problemas socioambientales. De esta manera se pone de manifiesto la validez de esta estrategia de trabajo colectivo para la apropiación de conocimientos, es decir, la comprensión de los graves problemas a los que nos enfrentamos, de sus estrechas vinculaciones y por todo ello la necesidad de indagar y poner en marcha propuestas que contribuyan a su superación.

Naturalmente, las aportaciones de los equipos de trabajo cooperativo pueden y deben ser completadas, proporcionándoles informaciones vinculadas a las mismas, fruto de investigaciones que han merecido el reconocimiento de la comunidad científica. Merece la pena, a este respecto, referirse a los estudios sobre límites planetarios que no deben ser sobrepasados, como garantía de un entorno compatible con el desarrollo de las sociedades humanas (Rockström et al., 2009).

Así, por ejemplo, Carl Folke (2013) hacía notar que la concentración de $\mathrm{CO}_{2}$ en la atmósfera ya había superado las 350 partes por millón (ppm), un límite planetario que sería necesario respetar para que las condiciones de vida en la Tierra permanezcan en un estado similar al del Holoceno y no se produzca una grave alteración del clima. Lamentablemente los datos muestran una evolución muy distinta: el año 2019 se llegó a las 400 ppm y ya hemos sobrepasado las 415ppm.

Los limites contemplados por Rockström et al. (2009) se refieren concretamente a los siguientes procesos: ritmo de extinción de la biodiversidad; ciclos de nitrógeno y fósforo (extraídos de la atmósfera para fabricar abonos agrícolas y otros usos); agotamiento del ozono estratosférico; acidificación de los océanos (el ritmo actual es muy superior al registrado durante los últimos 20 millones de años); utilización mundial del agua dulce (se han de garantizar unos flujos hídricos capaces de mantener el funcionamiento de los ecosistemas y sus servicios); cambios en el uso de los suelos (debidos, principalmente, al paso de bosques a terrenos agrícolas); contaminación atmosférica por aerosoles (que aumentan la concentración atmosférica de partículas en suspensión con efectos nocivos para la salud); contaminación por sustancias tóxicas (compuestos radiactivos, metales pesados o compuestos orgánicos de síntesis, inexistentes previamente en la naturaleza, que se han extendido por todo el planeta y afectan negativamente el estado de los ecosistemas); y el ya mencionado de la concentración del $\mathrm{CO}_{2}$ en la atmósfera.

Se trata de límites que han sido sobrepasados o están en vías de serlo debido a los problemas de contaminación, sobreconsumo, etc., que han sido señalados por los equipos y hemos resumido en la tabla 1. Límites planetarios que, al igual que los problemas, son interdependientes, de forma que sobrepasar cualquiera de ellos puede dar lugar a cambios ambientales bruscos — como está sucediendo ya con el cambio climático- y potenciar la gravedad de otros problemas.

Algunos equipos manifiestan su extrañeza de que estos estudios sobre límites planetarios no hayan incorporado ninguna consideración acerca de la población, cuando resulta obvio que todos los peligros de extralimitación están muy vinculados al tamaño creciente de esta población (y al hiperconsumo de una parte significativa de la misma). En realidad, les hacemos ver, hay una falta de atención generalizada a la problemática demográfica en los estudios y propuestas actuales sobre Sostenibilidad (Vilches y Gil Pérez, 2020). Cuando se pide a los equipos que hagan alguna conjetura explicativa de 
"El Antropoceno. Riesgos y oportunidades para las nuevas generaciones",

Amparo Vilches y Daniel Gil Pérez

Volumen 32 | Número especial | Páginas 55-72 |

http://dx.doi.org/10.22201/fq.18708404e.2021.4.80342

este hecho, la puesta en común lleva a señalar, además del desconocimiento de los datos y su consideración reduccionista, los prejuicios y la influencia que muchas tradiciones religiosas e ideológicas han tenido - y siguen teniendo- en el enfoque de la problemática demográfica.

Volviendo al contenido de la tabla 1, resulta difícil e innecesario distinguir entre causas y efectos en esta compleja problemática de la situación del mundo, porque están estrechamente relacionados y se potencian mutuamente. De hecho, en la reflexión de los equipos, esta distinción no suele producirse. Lo importante, pues, no es distinguir si un determinado aspecto constituye una causa o un efecto, sino tomar en consideración su conjunto como problemas a los que es preciso hacer frente. Y es esencial, sobre todo, y así lo perciben desde el principio los asistentes, dedicar la mayor atención a concebir las medidas, las acciones necesarias, para lograr la transición a sociedades sostenibles y satisfactorias.

Esta es la nueva tarea que les proponemos, para que amplíen y precisen lo que de forma más embrionaria suelen ya haber contemplado al reflexionar sobre los problemas:

Partiendo de los problemas considerados hasta aquí, concebir las transformaciones que convendría realizar para hacerles frente y poder avanzar en la transición a sociedades sostenibles, respetuosas de los Derechos Humanos del conjunto de los seres humanos y de las futuras generaciones, y de los equilibrios de la biosfera que condicionan nuestra supervivencia.

La puesta en común de las contribuciones de los equipos permite sintetizar las medidas que han propuesto y reforzarlas con las concebidas por la comunidad científica para hacer frente a los riesgos y graves problemas que caracterizan la actual situación de insostenible emergencia planetaria y aprovechar las oportunidades que se abren a las nuevas generaciones -incluida la actual- para avanzar en la construcción de sociedades sostenibles, satisfactorias para el conjunto de los seres humanos y respetuosas de la biodiversidad de la que formamos parte y que garantiza nuestra supervivencia. Expondremos esta síntesis - que viene a precisar lo que podemos entender como Transición a la Sostenibilidad- en el siguiente apartado.

\section{El Antropoceno como revolución civilizatoria de transición a sociedades sostenibles}

La complejidad de la situación en que nos encontramos, marcada, como hemos visto, por un conjunto de problemas estrechamente vinculados y que se potencian mutuamente, obliga a reconocer que, para contribuir a su superación, la Transición a la Sostenibilidad ha de comportar también todo un conjunto de medidas, igualmente vinculadas. La Transición a la Sostenibilidad aparece así como una pluralidad de transiciones, todas ellas imprescindibles. Resumiremos aquí brevemente las transiciones contempladas y debatidas en nuestros cursos y talleres, con el apoyo de algunas de las abundantes referencias científicas existentes:

- Transición a un consumo responsable: Adoptar estrategias de consumo responsable que reduzcan drásticamente el actual ritmo de agotamiento de todo tipo de recursos esenciales, desde minerales, bosques o bancos de pesca a las reservas de agua dulce y el mismo suelo cultivable. Un ritmo que en la actualidad es muy superior al de la regeneración de dichos recursos, cuando son renovables, o al de su posible 
"El Antropoceno. Riesgos y oportunidades para las nuevas generaciones",

Amparo Vilches y Daniel Gil Pérez

Volumen 32 | Número especial | Páginas 55-72 | http://dx.doi.org/10.22201/fq.18708404e.2021.4.80342

sustitución, cuando no lo son, por otros que sí lo sean. Se precisa, por tanto, pasar del hiperconsumo de una minoría -insostenible a escala planetaria- a un consumo responsable y solidario, accesible a todos los seres humanos (Mattar, 2012).

- Transición a una economía circular: Reducir el ritmo de producción de residuos contaminantes, asociados a la práctica totalidad de las actividades humanas, muy superior en la actualidad al de la capacidad del planeta para digerirlos. Es preciso y posible adoptar medidas de economía circular, que convierten los residuos en recursos, para evitar que una contaminación pluriforme y sin fronteras continúe envenenando suelos, ríos, mares y aire, afectando a la degradación de todos los ecosistemas (Stahel, 2019).

- Transición energética: Descarbonización, mediante la utilización de energías limpias y renovables, el incremento de la eficiencia de aparatos y procesos (industriales, agrícolas, etc.) y el ahorro energético, para acabar con el acelerado incremento de la concentración de gases de efecto invernadero en la atmósfera, que está provocando un cambio climático de graves consecuencias ya visibles. Una transición asociada a una nueva revolución industrial, basada en la utilización de las energías renovables, el hidrógeno para almacenar energía, los edificios como generadores locales de energía y el desarrollo de redes inteligentes de distribución de energía (Rifkin, 2010).

- Transición urbana: Remodelar el proceso de urbanización y transformar las ciudades en espacios saludables y que contribuyan a la sostenibilidad, evitando su crecimiento desordenado - acompañado del creciente abandono del mundo rural- que potencia los efectos de la contaminación (a causa del transporte, calefacción, acumulación de residuos, etc.) y el agotamiento de recursos (por la destrucción de terrenos agrícolas, el aumento de los tiempos de desplazamiento y consiguiente consumo de recursos energéticos, etc.). Favorecer su conexión con las zonas rurales y vegetación circundante, debidamente protegidas.

- Transición demográfica:Facilitarlosmediosquehaganposible unamaternidad y paternidad responsables, que programe el número de descendientes y el momento de tenerlos ("por elección, no por azar", como recomienda el Fondo de Población de Naciones Unidas), evitando los numerosísimos embarazos indeseados que causan los consiguientes perjuicios para los afectados — particularmente graves para millones de adolescentes-, amén de provocar el crecimiento de la población mundial, que puede estar ya cerca de sobrepasar la capacidad de carga del planeta (Vilches y Gil Pérez, 2020).

- Transición del antropocentrismo al biocentrismo: Revertir la acelerada degradación de ecosistemas y pérdida de biodiversidad, fruto, en buena medida, del crecimiento desmesurado de la especie humana (que acapara ya casi tanta producción fotosintética como la totalidad de las restantes especies) y de sus actividades depredadoras. Es preciso poner fin a una sexta gran extinción ahora en marcha, que amenaza con romper los equilibrios de la biosfera, con consecuencias tan graves como las pandemias provocadas por la transmisión a los seres humanos de virus procedentes de otras especies (zoonosis), como la provocada por el virus covid-19, y arrastrar en la extinción a la propia especie humana, causante de la misma. 
"El Antropoceno. Riesgos y oportunidades para las nuevas generaciones",

Amparo Vilches y Daniel Gil Pérez

Volumen 32 | Número especial | Páginas 55-72 |

- Transición de la imposición de la uniformidad cultural a la protección e impulso de su diversidad: Proteger la diversidad cultural y, muy en particular, las culturas campesinas milenarias. No debemos olvidar que la diversidad de culturas es la garantía de una pluralidad de respuestas a los problemas a los que ha de hacer frente la humanidad y que cada cultura no es solo una riqueza para el pueblo que la ha creado, sino un patrimonio de toda la humanidad.

- Transición tecnológica y laboral: Acompañar la innovación científicotecnológica con una transición laboral justa. Una sociedad sostenible, sin desequilibrios insolidarios, tiene como uno de sus requisitos fundamentales la existencia de puestos de trabajo digno para el conjunto de la ciudadanía. En un momento en que la innovación tecnológica (impulso de la digitalización, inteligencia artificial, robotización...) obliga a abandonar recursos e industrias contaminantes y favorece la supresión de numerosas tareas simples y de los correspondientes empleos (Frey y Osborne, 2017), se necesitan y son posibles nuevos yacimientos de ocupación (Vilches y Gil Pérez, 2016) que contribuyan a la transición justa hacia sociedades sostenibles y a satisfacer los derechos fundamentales de ciudadanas y ciudadanos. Cabe pensar así en el desarrollo de las energías renovables, la edificación ecológica, la protección y restauración de los ecosistemas, etc., sin olvidar la ocupación destinada a garantizar el acceso a servicios públicos fundamentales (salud, educación...) y a potenciar la producción y difusión cultural, como alternativa al insostenible consumismo de bienes materiales (Maaluf, 2009).

- Transición de la competitividad a la cooperación y universalización de los Derechos Humanos: Regular el sistema socioeconómico para que deje de estar presidido por la búsqueda del máximo beneficio particular a corto plazo, sin atender a sus repercusiones ambientales y sociales en un planeta de recursos finitos. Ello le convierte en responsable de problemas como los que venimos mencionando y de otros igualmente graves, como las dramáticas migraciones, y los conflictos y violencias causados por la competitividad y el afán de controlar los recursos esenciales. Es preciso hacer una transición hacia un modelo productivo basado en el bien común, sin paraísos fiscales, sin transgresión de los límites del planeta, respetuoso de la diversidad biológica y cultural y de las tres generaciones de Derechos Humanos (incluido el derecho a un ambiente saludable), poniendo fin a los desequilibrios insolidarios -insostenibles y éticamente inaceptables- entre una quinta parte de la humanidad impulsada al hiperconsumo depredador y miles de millones de personas que sufren condiciones de vida insoportables que llegan hasta provocar la muerte por falta de infraestructuras sanitarias e incluso por inanición (Costanza et al., 2013).

- Transición en las relaciones internacionales: Avanzar hacia una gobernanza plenamente democrática en todos los niveles, desde el más local al planetario, para mejor hacer frente a los problemas 'glocales' (a la vez globales y locales), que incorpore a las legislaciones el respeto y la universalización de los Derechos Humanos y sustituya la competitiva anteposición de valores e intereses particulares (económicos, étnicos, religiosos, de género...) por la cooperación en beneficio de toda la humanidad y de las generaciones futuras. 
"El Antropoceno. Riesgos y oportunidades para las nuevas generaciones",

Amparo Vilches y Daniel Gil Pérez

Volumen 32 | Número especial | Páginas 55-72 |

http://dx.doi.org/10.22201/fq.18708404e.2021.4.80342

Hoy se sabe que estas transiciones son todas y cada una de ellas imprescindibles, como ya hemos señalado, porque los problemas que pretenden resolver están estrechamente vinculados y se potencian mutuamente, resultando imposible resolver ninguno de ellos sin tener en cuenta los restantes. La ausencia generalizada de esta visión global, holística, en la ciudadanía y muy particularmente en estudiantes, docentes y responsables políticos y económicos, constituye un serio obstáculo para la adopción de medidas y acciones realmente efectivas. Ello obliga a incorporar otras medidas necesarias para hacer posible la transición a la Sostenibilidad:

- Es necesario integrar las aportaciones a la Sostenibilidad de las distintas disciplinas científicas, desarrollos tecnológicos, corrientes de pensamiento, movimientos sociales, etc., que han abordado separadamente los diversos problemas socioambientales. Ello justifica el surgimiento y potente desarrollo de la Ciencia de la Sostenibilidad, fruto de una nueva revolución científica que integra campos de pensamiento y acción hasta aquí inconexos, potenciando las innovaciones necesarias y evitando que supuestas soluciones a problemas puntuales generen nuevos obstáculos a la transición a la Sostenibilidad.

Merece la pena detenerse mínimamente en las características de esta nueva ciencia o, mejor, de esta nueva orientación para enfocar problemáticas complejas como la que supone la actual situación de emergencia planetaria, que demanda el tratamiento global, sin reduccionismo ni olvidos, del sistema cada vez más complejo constituido por las sociedades humanas y los sistemas naturales con los que interaccionan y de los que, en definitiva, forman parte (Garritz, Vilches y Gil Pérez, 2014; Vilches y Gil Pérez, 2015):

- La nueva orientación ha de ser profundamente interdisciplinar, puesto que aborda retos complejos en los que intervienen problemas muy diversos, pero estrechamente vinculados, ninguno de los cuales puede ser resuelto aisladamente.

- Se ha comprendido igualmente que para hacer posible la transición a la Sostenibilidad es necesario incorporar a la investigación y toma de decisiones a ciudadanas y ciudadanos que no forman parte del ámbito académico pero cuyos objetivos, conocimientos y capacidad de intervención resultan imprescindibles para definir y desarrollar estrategias viables. Se trata, pues, de una orientación transdisciplinar, que promueve la participación ciudadana.

- Las estrategias concebidas han de responder a una perspectiva amplia, tanto espacial como temporalmente. Ello implica que la perspectiva sea espacialmente "glocal" y que temporalmente contemple tanto el corto como el medio y el largo plazo, esforzándose en anticipar posibles riesgos y obstáculos y en aprovechar tendencias positivas.

Planteamientos con esas características permiten evitar las contradicciones que a menudo afectan a medidas adoptadas para resolver problemas puntuales en el tiempo o en el espacio, que olvidan su conexión con otros problemas.

Por último, pero no menos importante, nos referiremos a la necesidad de potenciar la Educación para la Sostenibilidad:

- Impulsar la Educación para la Sostenibilidad, tanto desde los centros educativos (en los diferentes niveles y materias, desde infantil hasta la universidad), como desde los medios de difusión, museos, documentales... y en nuestras relaciones sociales, para proporcionar una percepción holística adecuada de la situación del mundo, sus causas y medidas que se requiere adoptar, local y globalmente. Con 
"El Antropoceno. Riesgos y oportunidades para las nuevas generaciones",

Amparo Vilches y Daniel Gil Pérez

Volumen 32 | Número especial | Páginas 55-72 |

esta educación, a la que podemos y debemos contribuir todas las personas, se trata de potenciar la implicación y la participación ciudadana en la acción política para la toma de decisiones, en la adopción de dichas medidas y en el control de sus resultados en los diferentes ámbitos: consumo responsable, actividad profesional y acción ciudadana (Gil Pérez y Vilches, 2019).

La consideración de medidas como las aquí resumidas permite precisar qué entender por transición a la Sostenibilidad, mejor que debates más abstractos en torno a los significados de Sostenibilidad, Desarrollo Sostenible, Decrecimiento, Crecimiento Inclusivo, etc. Debates en los que resulta fácil caer en malentendidos y distorsiones y que terminan por confundir a la ciudadanía, dificultando su implicación en la adopción de las medidas necesarias. Al centrarse, en cambio, en el conjunto de los problemas y vías de solución, como hemos intentado hacer aquí, se pueden apreciar las convergencias entre las propuestas de quienes - con una u otra denominación- se plantean hacer frente a la insostenible situación de emergencia planetaria que caracteriza el Antropoceno.

Abordaremos, para terminar, una cuestión fundamental, ¿hasta qué punto puede esperarse que las nuevas generaciones hagan suyo un proyecto tan ambicioso y exigente como el que supone la transición a la Sostenibilidad?

\section{La Transición a la Sostenibilidad como proyecto movilizador y generador de valores}

Hasta aquí hemos estudiado colectivamente los graves problemas de origen antrópico que han conducido a denominar Antropoceno a esta etapa de la evolución de nuestro planeta, y hemos contemplado el conjunto de medidas consideradas necesarias para hacerles frente y lograr la transición a sociedades sostenibles. Ahora planteamos a los equipos esta cuestión clave:

\footnotetext{
¿Puede esperarse que las nuevas generaciones, comenzando por la actual juventud, hagan suyo un proyecto tan ambicioso y exigente como el que supone, como acabamos de ver, la transición a la Sostenibilidad?
}

La discusión generada en los equipos por esta cuestión resulta habitualmente muy viva, incluso apasionada, haciendo emerger en algunas intervenciones, desconfianzas y culpabilizaciones, fruto de experiencias vitales, pero también de mitos sociales muy enraizados, acerca de una juventud supuestamente carente de inquietudes e interés por el bien común; algo que otras intervenciones cuestionan, atribuyendo los comportamientos criticados de falta de ideales, incapacidad de esfuerzo, etc., a estructuras sociales guiadas por los intereses a corto plazo de una minoría, que dejan a buena parte de la ciudadanía - y muy particularmente a los jóvenes- sin perspectivas, contribuyendo a la degradación social y ambiental. Reencontramos aquí, como puede apreciarse, uno de los graves problemas estudiados.

Resulta oportuno incidir en este debate aportando algún breve texto con, por ejemplo, las reflexiones del economista y sociólogo argentino Bernardo Kliksberg (2007), considerado el pionero de la ética para el desarrollo y estudioso de los mitos sobre la juventud latinoamericana. Kliksberg cuestiona documentadamente esos mitos, afirmando que los jóvenes "tienen un potencial inmenso, como lo han demostrado cuando se crean condiciones propicias. El tema es generarlas". Y generar esas condiciones, añade, supone dar a la juventud ocasión de "hacer cosas en conjunto por metas de interés colectivo". El corolario resulta lógico: ¿qué meta de interés colectivo puede ser más relevante hoy para los y las jóvenes (y, en realidad, para los ciudadanos y ciudadanas de todas las edades) 
"El Antropoceno. Riesgos y oportunidades para las nuevas generaciones",

Amparo Vilches y Daniel Gil Pérez

Volumen 32 | Número especial | Páginas 55-72 |

que hacer frente a la grave situación actual de emergencia planetaria y contribuir a la construcción de una sociedad sostenible? De este modo, la pregunta acerca de hasta qué punto se puede confiar o no en las nuevas generaciones para hacer posible la transición a la Sostenibilidad deja paso a la de cómo generar las condiciones que permitan e impulsen a las nuevas generaciones a implicarse en una profunda revolución cultural (personal, tecnocientífica, política...) para dar respuesta al conjunto de problemas a los que la humanidad ha de hacer frente hoy.

La respuesta no es obvia, no existe una fórmula sencilla para lograrlo. Como se intenta hacer en los talleres que estamos presentando, se precisa dar a conocer la gravedad de la situación, sus causas y la necesidad de participación ciudadana en la adopción de las medidas correctoras, lo que se convierte en un reto capaz de dar sentido a nuestras vidas. Pero la acción educativa no puede limitarse al logro de dicha comprensión, dando por sentado que ello conducirá a cambios efectivos en los comportamientos: un obstáculo fundamental para lograr la implicación de los ciudadanos y ciudadanas en la construcción de un presente y un futuro sostenibles es limitar las acciones educativas al estudio conceptual. Es necesario establecer compromisos de acción en los centros educativos y de trabajo, en los barrios, en las propias viviendas... para poner en práctica algunas de las medidas y realizar el seguimiento de los resultados obtenidos. Estas acciones debidamente evaluadas (y, sobre todo, autoevaluadas) se convierten en el mejor procedimiento para una comprensión profunda de los retos y en un impulso para nuevos compromisos.

Es cierto que los participantes en cursos y talleres de educación para la sostenibilidad a menudo expresan dudas acerca de la efectividad que pueden tener los comportamientos individuales, los pequeños cambios en nuestras costumbres, en nuestros estilos de vida, que la educación puede favorecer: Los problemas de agotamiento de los recursos energéticos y de contaminación — suelen afirmar, por ejemplo- son debidos, fundamentalmente, a las grandes industrias; lo que cada uno de nosotros puede hacer al respecto es, comparativamente, insignificante.

Cálculos bien sencillos, que los propios participantes pueden hacer, muestran, sin embargo, que, si bien las pequeñas reducciones de consumo energético, por poner un ejemplo, suponen un ahorro per cápita pequeño, al multiplicarlo por los millones de personas que pueden realizar dicho ahorro, este llega a representar cantidades ingentes de energía, con su consiguiente reducción de la contaminación. Hay que insistir, por tanto, en que no solo no es cierto que nuestras pequeñas acciones sean insignificantes e irrelevantes, sino que se trata de medidas necesarias, imprescindibles, si queremos contribuir al avance hacia sociedades más justas y sostenibles con la necesaria y cada vez mayor implicación de la ciudadanía. Y hay que dejar claro, por otra parte, que las posibilidades de nuestra intervención no se reducen a unas pocas acciones de consumo responsable, sino que se extienden también a lo que podemos hacer como profesionales y en general como ciudadanos y ciudadanas responsables. No basta con ajustar nuestro comportamiento a las conocidas 3R ("Reducir", "Recuperar/Reutilizar" y "Reciclar" como parte de una economía circular). Es preciso, igualmente, implicarse en la utilización y promoción de tecnologías respetuosas con el medio y las personas, contribuir a la educación y acción ciudadana (todos somos educadores y educandos a través de nuestras relaciones sociales) y participar en acciones sociopolíticas para la sostenibilidad. Y todo ello puede ser programado y sometido a autoevaluación. 
"El Antropoceno. Riesgos y oportunidades para las nuevas generaciones",

Amparo Vilches y Daniel Gil Pérez

Volumen 32 | Número especial | Páginas 55-72 |

http://dx.doi.org/10.22201/fq.18708404e.2021.4.80342

Hoy tenemos a nuestra disposición numerosos ejemplos de lo que puede hacerse como consumidores privados, como profesionales y como sujetos políticos. La obra de Mario Molina, a la que nos hemos referido en la introducción de este artículo -su decisión de regresar a México, abandonando una excelente posición académica en EEUU, para asociar su actividad científica a políticas públicas de protección al medio ambiente- constituyen un excelente ejemplo en el campo profesional y ciudadano. Como lo es - por citar otro ejemplo relevante- la decisión de los sindicatos de dejar de oponerse a cambios tecnológicos que amenazan miles de puestos de trabajo (abandono, por ejemplo, del carbón y el petróleo, robotización de tareas simples, etc.), para comprender que no se trata de oponerse a dichos cambios, sino de apoyar "transiciones justas", reclamando que se realicen promoviendo las reconversiones y formaciones necesarias (Poschen, 2017) respetuosas de los Derechos Humanos y del medio ambiente. De hecho, las organizaciones sindicales y profesionales se implicaron decisivamente en el establecimiento de los Objetivos de Desarrollo Sostenible (ODS), aprobados por la Asamblea General de Naciones Unidas en 2015, junto con la Agenda 2030 para hacerlos avanzar.

Merece la pena recordar que el establecimiento de los ODS (17 grandes objetivos universales que se concretan en 169 metas), gracias a una amplia participación de instituciones académicas, medios de comunicación, sindicatos, sector privado, ONG, sociedad civil y líderes políticos, se realizó con el propósito explícito de hacer frente a todos los grandes problemas señalados convergentemente por la comunidad científica y otros colectivos, para contribuir a hacer posible la satisfacción en todo el mundo del conjunto de Derechos Humanos Universales, pero evitando debates nominalistas acerca de qué entender por Desarrollo Sostenible, Decrecimiento, Crecimiento Inclusivo. Fue este centrarse en medidas y objetivos claros, para hacer frente al conjunto de problemas, lo que permitió el consenso que certificó la Asamblea General de Naciones Unidas de 2015. Ello ha convertido los ODS en un verdadero programa de Transición a la Sostenibilidad al que han ido sumándose instituciones científicas, educativas, culturales, ONG, organizaciones sindicales y ciudadanas... y, en general, todos aquellos colectivos que han comprendido la necesidad y urgencia de hacer frente a la insostenible situación de emergencia planetaria con medidas fundamentadas y consensuadas internacionalmente. Esa es también nuestra opción y nuestra propuesta para convertir los riesgos del Antropoceno en oportunidad de progreso para el conjunto de la humanidad y, muy especialmente, para las nuevas generaciones, comenzando por la juventud actual, tan necesitada de metas de interés colectivo capaces de abrirle perspectivas y de dar sentido a su existencia.

\section{Referencias}

Comisión Mundial del Medio Ambiente y del Desarrollo (1988). Nuestro futuro común. Madrid, España: Alianza.

Costanza, R., Alperovitz, G., Daly, H., Farley, J., Franco, C., Jackson, T., Kubiszewski, I., Schor, J. y Victor, P. (2013). Construir una economía sostenible y deseable, integrada en la sociedad y en la naturaleza. En Worldwatch Institute, The State of the World 2013: Is Sustainability Still Possible? New York, USA: W.W. Norton.

Diamond, J. (2006). Colapso. Barcelona, España: Debate. 
Frey, C. B. and Osborne, M. A. (2017). The future of employment: How susceptible are jobs to computerization? Technological Forecasting and Social Change, 114, 254-280.

Garritz, A., Vilches, A. y Gil Pérez, D. (2014). Una revolución científica a la que Educación Química quiere contribuir. Educación Química, 25 (3), 290-291.

Gil Pérez, D. y Vilches, A. (2019). La comprensión e impulso de la Sostenibilidad: un requisito imprescindible para una acción educativa y ciudadana eficaz. Revista de Educación Ambiental y Sostenibilidad, 1(2), 2101.

Gil- Pérez, D., Vilches, A., Edwards, M., Praia, J., Marques, L. and Oliveira, T. (2003). A proposal to enrich teachers' perception of the state of the world. First results. Environmental Education Research, 9(1), 67-90.

Gore, A. (2007). Una verdad incómoda. Barcelona, España: Gedisa.

Kliksberg, B. (2007). Mitos sobre la juventud latinoamericana. En Sen, A. y Kliksberg, B. Primero la gente. Barcelona, España: Ed.Deusto. Capítulo 8.

Maaluf, A. (2009). El desajuste del mundo. Cuando nuestras civilizaciones de agotan. Madrid, España: Alianza Editorial.

Mattar, E. (2012). Políticas públicas para un consumo más sostenible. En Worldwatch Institute La situación del mundo 2012. Hacia una prosperidad sostenible. Barcelona, España: Icaria.

Pearce, F. (2007). La última generación. Benasque, España: Barrabes

Poschen, P. (2017).Trabajo decente, empleos verdes y economía sostenible: Soluciones para el cambio climático y el desarrollo sostenible. Madrid, España: Plaza y Valdés Editores y OIT. [Publicado inicialmente en inglés, en 2015, con el título Decent Work, Green Jobs and the Sustainable Economy].

Rifkin, J. (2010). La civilización empática. Barcelona, España: Paidós.

Rockstrom, J., Steffen, W., Noone, K.J., Persson, A., Chapin, F.S., Lambin, E.F., Lenton, T.M., Scheffer, M., Folke, C. and Schellnhuber, H.J. (2009). A Safe Operating Space for Humanity, Nature, 461, 472-475.

Sachs, J. (2008). Economía para un planeta abarrotado. Barcelona, España: Debate.

Stahel, W. R. (2019). Economía circular para todos. Conceptos básicos para ciudadanos, empresas y gobiernos. Oxon, UK: Taylor \& Francis Group.

Vilches, A. y Gil Pérez, D. (2011). Papel de la Química y su enseñanza en la construcción de un futuro sostenible, Educación Química, 22 (2), 103-11.

Vilches, A. y Gil-Pérez, D. (2015). Ciencia de la Sostenibilidad: ¿Una nueva disciplina o un nuevo enfoque para todas las disciplinas? Revista Iberoamericana de Educación (RIE), 69 (1), 39-60.

Vilches, A. y Gil-Pérez, D. (2016). La transición a la Sostenibilidad como objetivo urgente para la superación de la crisis sistémica actual. Revista Eureka sobre Enseñanza y Divulgación de las Ciencias, 13 (2), 395-407. 
Vilches, A. y Gil Pérez, D. (2020). The Role of Demography in the Transition to Sustainable Societies, Ciência \& Educação (Bauru), v. 26, e20016, 1-17.

Vitousek, P., Mooney, H., Lubchenco, J. and Melillo, J. (1997). Human Domination of Earth's Ecosystems, Science, 277, 5325, 494-499.

Zalasiewicz, J., Williams, M., Smith, A., Barry, T.L., Coe, A.L., Bown, P.L., Brenchley, P., Cantrill, D., Philip Gibbard, A.G., Gregory, F.H., Hounslow, M.W., Kerr, A.C., Pearson, P., Knox, R., Powell, J., Waters, C., Marshall, J., Oates, M., Rawson, P. and Stone, P. (2008). Are we now living in the Anthropocene? GSA Today, 18, 2, 4-8. 